\title{
ANÁLISE DA VIABILIDADE TÉCNICA DE REUTILIZAÇÃO DO EFLUENTE DE UMA LAVANDERIA INDUSTRIAL
}

\author{
Frank Pavan de Souza
}

Mestre em Engenharia Ambiental / IFF / RJ

frankpavan@gmail.com

\section{Samyla Mota Ribeiro Areas}

Graduada em Engenharia de Produção / ISECENSA/ RJ

samylamota@hotmail.com

\section{Mônica Pertel}

Doutora em Engenharia Civil/ UFRJ/ RJ

mpertel@gmail.com

\section{RESUMO}

Nos dias atuais, buscar alternativas para a preservação da água é essencial para que esse recurso não se torne escasso. Este trabalho tem por objetivo analisar a viabilidade técnica de reutilização do efluente proveniente do processo de lavagem de jeans em uma indústria no Município de Campos dos Goytacazes/RJ. Foi desenvolvido um estudo de caso onde foram realizadas entrevistas semiestruturadas para descrever o processo de lavagem de jeans e o processo de tratamento do efluente. Foram realizadas análises físico-químicas e bacteriológicas do efluente no final da produção e após o tratamento para verificar a viabilidade da sua reutilização no processo de lavagem. Os resultados foram avaliados a partir das análises físico-químicas e bacteriológicas baseando-se na NBR 13969/97 e no Manual de Conservação e Reúso de Água em Edificações elaborado pela ANA e FIESP e permitiram verificar que o efluente tratado não pode ser reutilizado no processo de lavagem de jeans, uma vez que alguns parâmetros ficaram fora dos padrões de qualidade estabelecidos.

Palavras-chave: Água residuária. Reúso. Qualidade da água.

\section{INTRODUÇÃO}

A água é um recurso natural essencial para a manutenção e existência da vida. Todos os seres vivos dependem dela para sua sobrevivência e para garantir a permanência da espécie. Além disso, ela é fundamental para os processos produtivos e exerce uma influência decisiva na qualidade de vida das populações (BARBOSA, 2008).

O Brasil apresenta uma situação privilegiada quanto à disponibilidade dos recursos hídricos. De acordo com Machado (2004), o Brasil possui cerca de 12\% de toda água doce disponível no planeta, no entanto em uma distribuição irregular no país. 


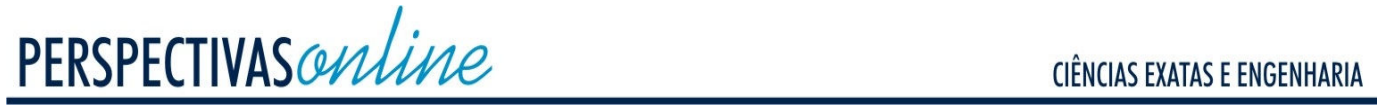

A disponibilidade de água apresenta-se como um dos mais graves problemas do século XXI devido ao crescimento populacional, irregularidade na distribuição dos recursos hídricos, crescente industrialização e degradação dos mananciais disponíveis (MENEZES, 2005).

A escassez hídrica é motivo de preocupação pelo fato de que 1,2 bilhões de pessoas residem em zonas de déficit de água e cerca de 500 milhões correm o risco de exposição à escassez a curto prazo (PINHEL et al 2007).

A escassez e o uso inadequado dos recursos hídricos representam um risco crescente ao desenvolvimento sustentável e à proteção do meio ambiente. A saúde coletiva e o bem-estar, a segurança alimentar, o desenvolvimento industrial e dos ecossistemas, dos quais todos dependem, estão ameaçados, se os recursos hídricos não forem gerenciados de forma mais eficiente, no presente e no futuro, do que o foram no passado (BEEKMAN, 1999). É cada vez mais necessária a implementação de políticas públicas para a gestão eficiente dos recursos hídricos, além de ações voltadas à sustentabilidade. (PERTEL, 2009).

Diante deste cenário, o reúso da água é considerado uma alternativa para reduzir o consumo e o desperdício, pois reduz a quantidade de água retirada da natureza para os processos desenvolvidos pelas empresas, contribuindo para a preservação dos recursos hídricos e prevenção da escassez (LEITE, 2003).

\section{METODOLOGIA}

Foi realizada uma entrevista semi-estruturada com o supervisor de produção da Indústria Sr. Kaio César no sentido de descrever o processo de lavagem de roupas. Para realizar a descrição do tratamento da água foi realizada entrevista semi-estruturada com a Química da lavanderia. Além disso, foram captadas imagens in loco para permitir uma melhor visualização do local de estudo $e$ dos processos descritos. As análises do efluente foram realizadas no Laboratório do ISECENSA, FUNDENOR e LEMA - UFRJ a partir de coletas de água da lavanderia. Os parâmetros físicoquímicos analisados foram: $\mathrm{pH}$, cor, turbidez, cloro residual, óleos e graxas, $\mathrm{DBO}$, nitrogênio amoniacal, nitrato, nitrito, fósforo total, sólidos totais, sólidos fixos e sólidos voláteis. Os resultados foram avaliados a partir das análises físico-químicas e bacteriológicas baseando-se na NBR 13.969 e no Manual de Conservação e Reúso de Água em Edificações elaborado pela ANA e FIESP (2005), que definem classes para o reúso quanto a sua finalidade e estabelecem parâmetros e seus valores de acordo com a classe definida.

Durante a pesquisa houve dificuldades para a realização da análise de todos os parâmetros no Laboratório do ISECENSA, sendo então necessário realizar estas análises em outros laboratórios.

\section{RESULTADOS \& DISCUSSÃO}

\subsection{Descrição da lavanderia industrial}

Esta pesquisa foi aplicada em uma lavanderia industrial de jeans localizada na cidade de Campos dos Goytacazes- RJ. As atividades de campo, bem como as imagens e informações técnicas apresentadas no contexto, foram autorizadas pela empresa. Mesmo autorizando a realização da pesquisa, a direção da indústria não permitiu que seu nome fosse divulgado para preservar suas estratégias. 


\section{PERSPECTIVAS online GiêACIAS EXATAS E ENGENHARIA}

Atualmente a lavanderia possui 44 funcionários, sendo um Administrador, uma Química e três Supervisores de Produção. Foi informado que a produção de lavagem mensal é em torno de 23.000 peças e o consumo de água diário da lavanderia é de aproximadamente 88.000 litros, considerando que a cada 50 peças são utilizados 4190 litros de água como informado pela indústria.

\subsection{Descrição do processo de lavagem de jeans}

A lavanderia possui 5 máquinas de lavar sendo, 3 verticais com capacidade $100 \mathrm{~kg}$ de roupa e 2 horizontais com capacidade de $200 \mathrm{~kg}$. Estas máquinas desempenham as mesma funções e onde são realizados os processos de desengomagem, enxágüe, estonagem, amaciamento e neutralização, 2 centrífugas e 4 secadoras, conforme Figuras 1 A à 1D.

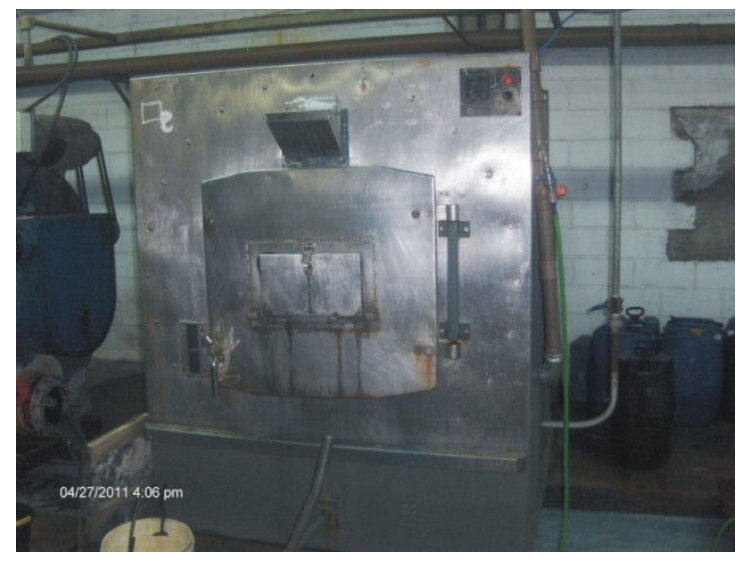

Figura 1 A: Máquina de lavar vertical Fonte: Elaboração própria, 2011

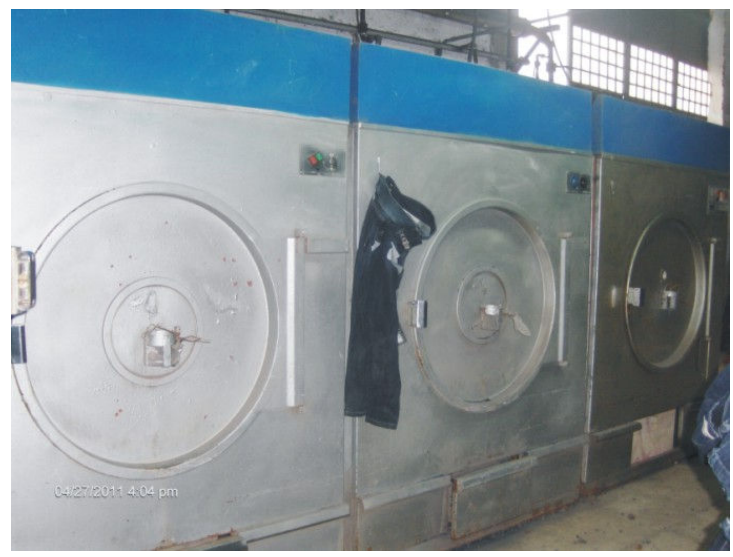

Figura 1 C: Secadoras

Fonte: Elaboração própria, 2011

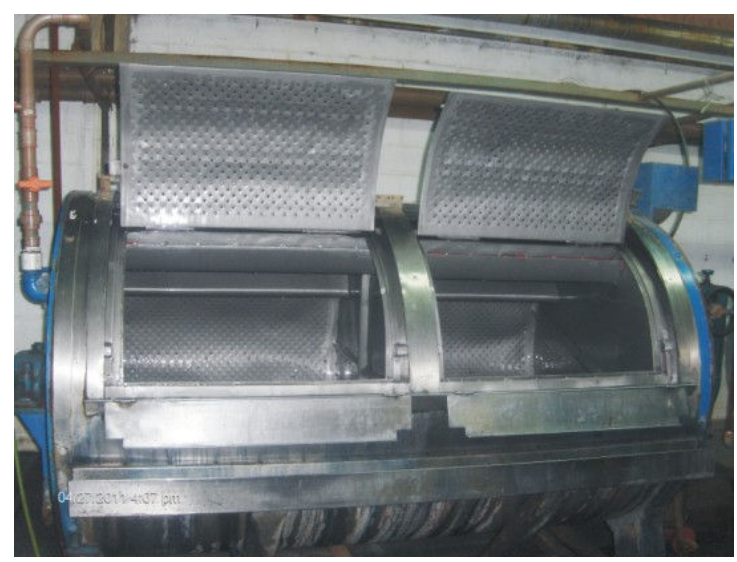

Figura 1 B: Máquina de lavar horizontal Fonte: Elaboração própria, 2011

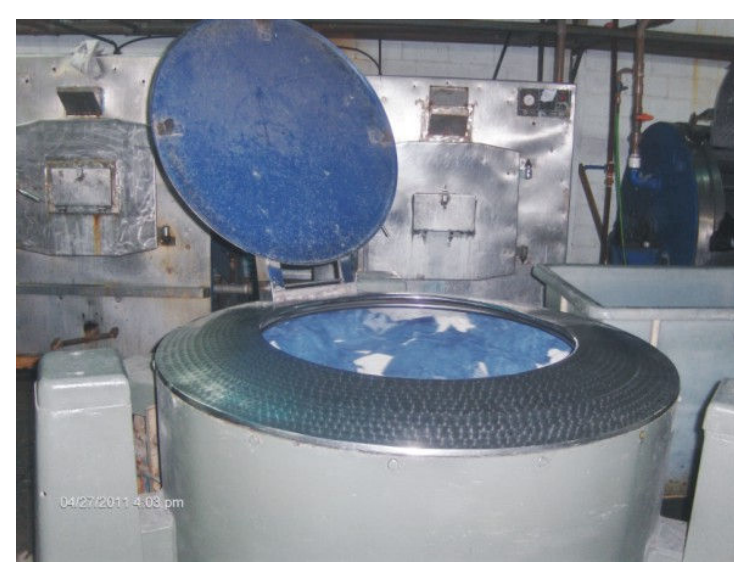

Figura 1D: Centrífuga

Fonte: Elaboração própria, 2011

No início do processo, as roupas seguem para duas caixas de umectação (figura 2) com água e antiquebradura. Essa umectação é realizada para retirar o excesso de goma do jeans fazendo com que não ocorram marcas indesejadas no produto final. A água da caixa de umectação é trocada a cada dia. 


\section{PERSPECTIVAS online cIênCIAS EXatas E ENGENHARIA}

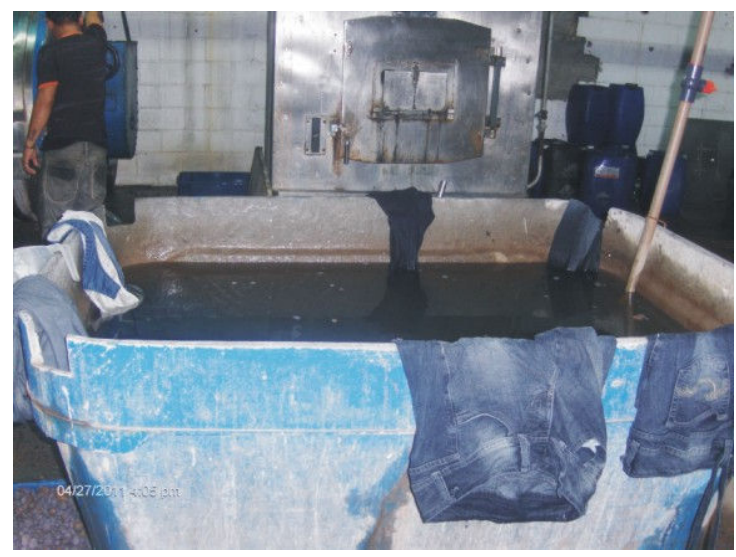

Figura 2: Caixa de umectação

Fonte: Elaboração própria, 2011

Em seguida, as peças seguem para a máquina de lavar para o processo de desengomagem onde são utilizadas a enzima alfamilase e o sabão antimigrante para remover o restante da goma que a caixa de umectação não retirou. Nessa etapa do processo são utilizados 350 litros de água. Após o processo de desengomagem, são realizados 3 enxágues. Vale ressaltar que todos os produtos são lavados ao mesmo tempo num mesmo processo. Cada enxágue consome 360 litros de água, portanto 1080 litros.

A próxima etapa do processo é a estonagem, onde são utilizadas pedras de argila e a enzima celulase híbrida granulada concentrada para desgastar o tecido e clareá-lo. São utilizados $0.5 \%$ desta enzima para cada quilograma de roupa. O tempo neste processo varia de acordo com a cor do jeans desejada (clara ou escura) e são utilizados 200 litros de água independente da cor pretendida. Após este processo, são realizados 3 enxágues novamente. Em seguida, as peças seguem para o processo de centrifugação para retirar o excesso de água e depois para a secagem.

Ao sair da secadora, as peças seguem para o setor de diferenciação do jeans se for realizado o processo de used. Esse processo é realizado em cerca de $90 \%$ das peças e refere-se à criação manual de manchas no jeans com permanganato de potássio realizadas com uma pistola nos lugares desejados. As peças que não passarem pelo processo de used, seguem diretamente para os processos de amaciamento, centrifugação, secagem e acabamento.

As peças que foram realizadas o processo de used retornam para a máquina de lavar, onde as mesmas serão neutralizadas com o metabissulfito de sódio para retirar o tom roxo do permanganato de potássio. São utilizados 200 litros de água e após o processo de neutralização são realizados 3 enxágues. Em seguida, as peças passam pelo processo de amaciamento onde são consumidos 200 litros de água e posteriormente, seguem para a centrífuga e secadora. Após o processo de lavagem, as peças seguem para o setor de acabamento onde são passadas e etiquetadas. Todas as etapas do processo estão representadas pela Figura 3. 


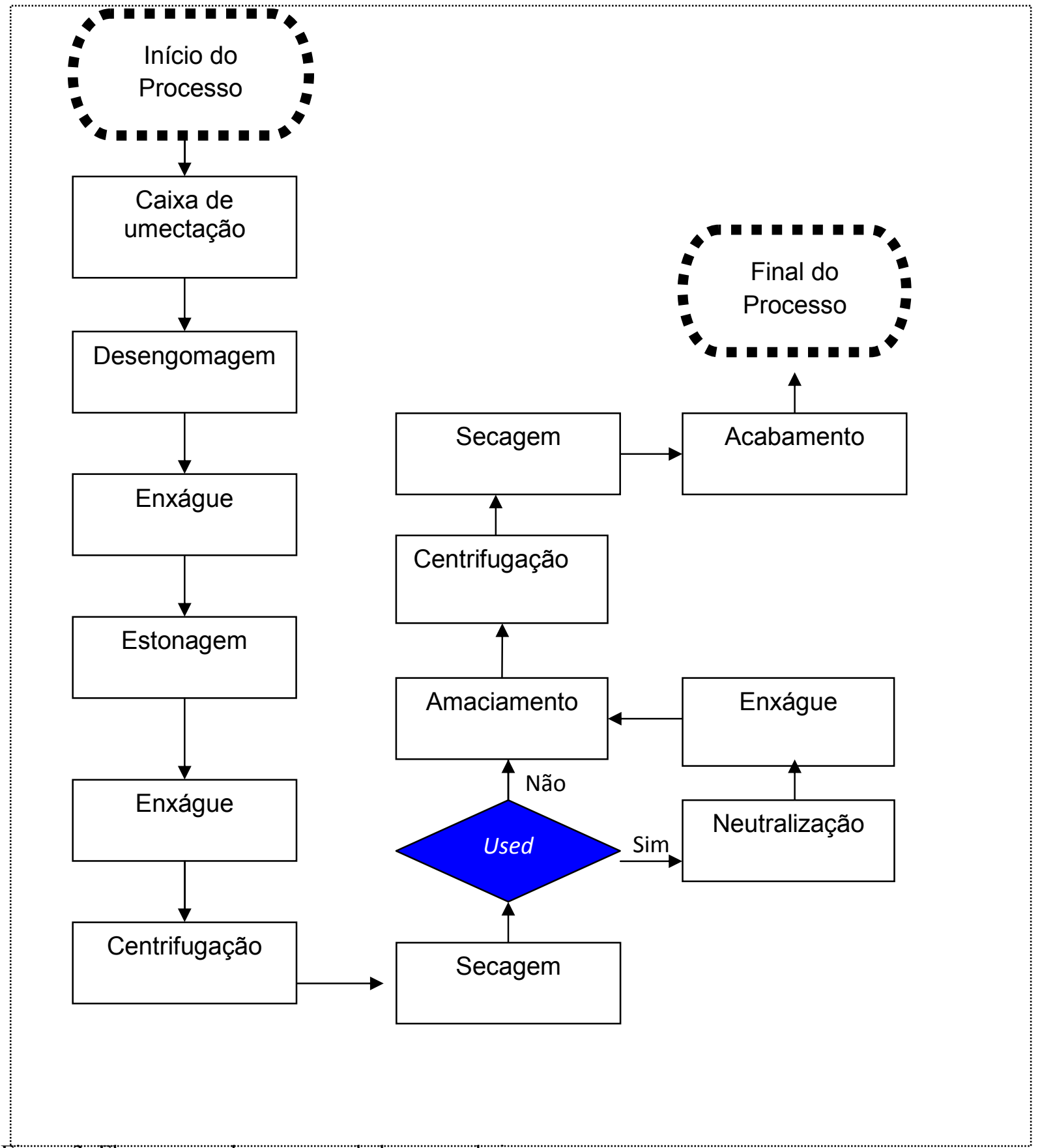

Figura 3: Fluxograma do processo de lavagem de jeans.

Fonte: Elaboração própria, 2011

\subsection{Descrição do processo de tratamento do efluente}

A lavanderia realiza o tratamento do efluente proveniente do processo de lavagem de jeans em uma estação própria localizada na área interna da indústria, que está representada nas Figuras $4 \mathrm{a}, \mathrm{b}$ e c. Durante o processo, são realizadas análises do efluente pela Química responsável. 

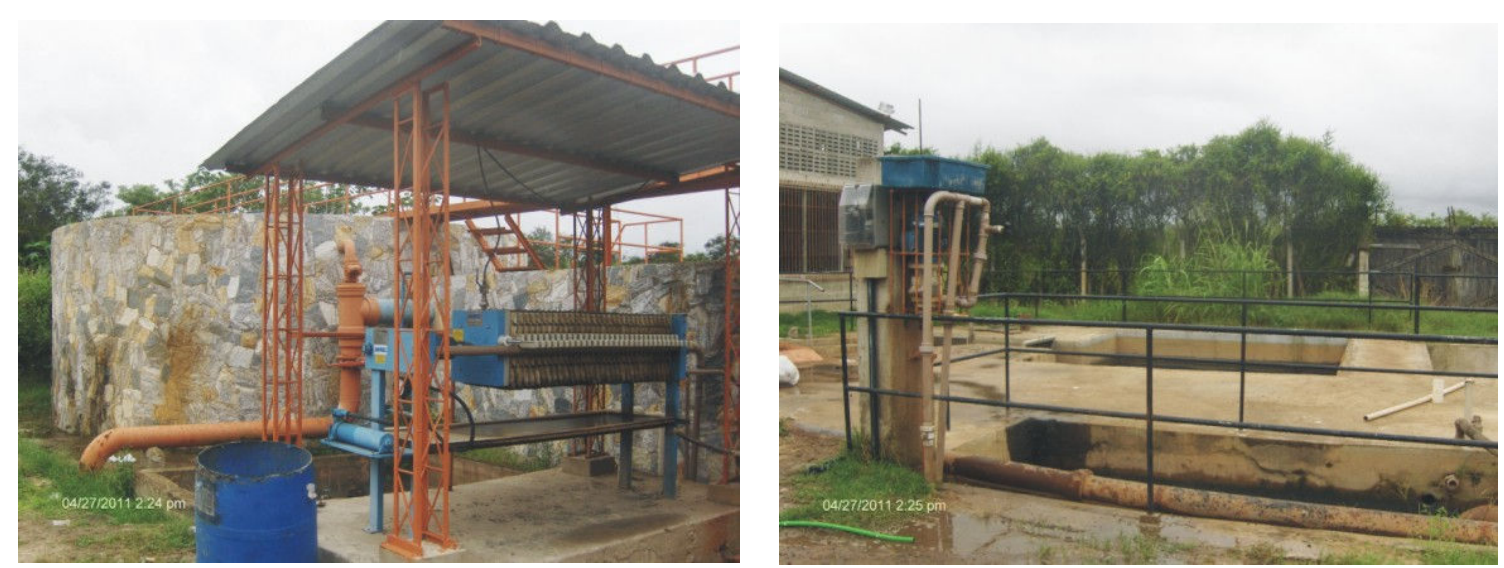

Figura 4 A: ETE

Fonte: Elaboração própria
Figura 4 B: ETE

Fonte: Elaboração própria

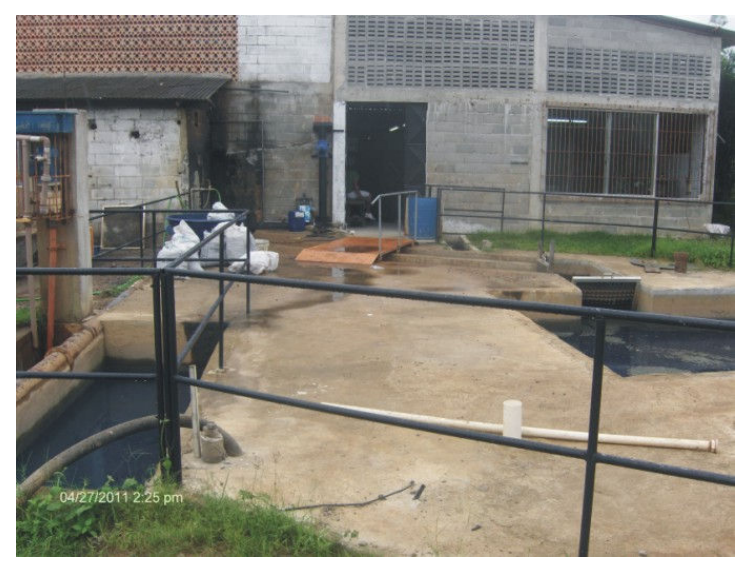

Figura 4 C: ETE

Fonte: Elaboração própria

No início do processo de tratamento, o efluente é conduzido para um tanque com três desarenadores que retém areia e sólidos suspensos existentes. Os grãos de areia e os sólidos presentes se depositam no fundo do tanque de sedimentação.

Após essa etapa, o efluente segue para o tanque de equalização que serve para torná-lo mais homogêneo, fazendo com que as próximas etapas do processo de tratamento ocorram sem altas variações nos parâmetros. Em seguida, o efluente é conduzido para um reservatório onde fica armazenado, e posteriormente segue para o tanque de decantação por meio de bombeamento.

No tanque de decantação, há um registro onde pode ser regulada a vazão da água. O efluente que chega ao tanque passa por um reservatório onde são adicionados os seguintes produtos químicos: hidróxido de sódio para ajustar o $\mathrm{pH}$ da água; sulfato de alumínio que auxilia na floculação, processo químico onde as partículas em suspensão se tornam pequenos flocos, decantando em seguida; descolorante para a auxiliar no clareamento da água; e polímero que concede peso aos flocos para que estes possam se sedimentar. A quantidade de produtos utilizados nesta etapa do processo varia de 
acordo com a necessidade de regular a cor e pH. O tanque de decantação é dividido em 5 partes por onde o efluente percorre após a adição dos produtos químicos para que ocorra a sedimentação dos flocos.

A próxima etapa do processo é a filtração, onde são removidas partículas sólidas que não foram eliminadas nas etapas anteriores. Após esta etapa, o efluente segue para o reservatório final onde fica armazenado para em seguida, ser lançado no córrego, conhecido popularmente por Córrego do Coqueiro, apresentado na Figura 5. É importante ressaltar que a Empresa não possui outorga para lançamento junto ao Órgão Ambiental e que a lama que fica no fundo dos tanques de tratamento vai para um reservatório onde é retida por um filtro prensa. Após, esta é removida do filtro é levada para um caminhão de lixo.

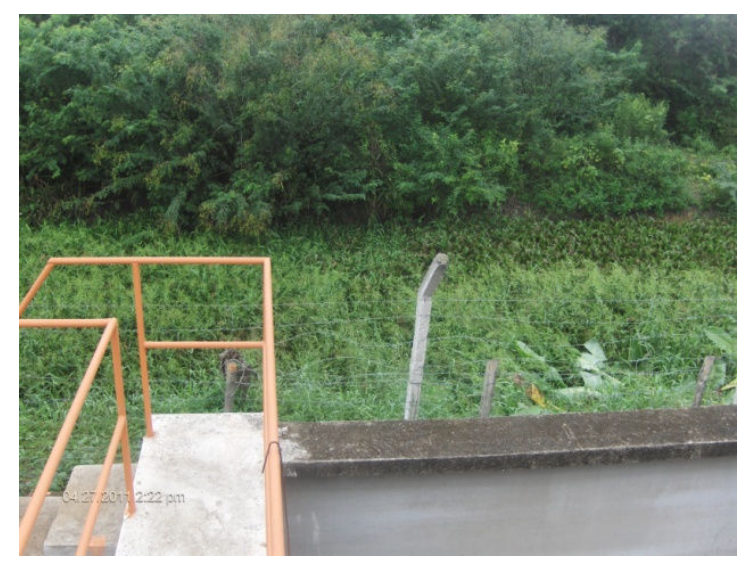

Figura 5: Córrego

Fonte: Elaboração própria, 2011

$\mathrm{O}$ processo de tratamento tem a duração aproximada de $2 \mathrm{~h}$ e todas as etapas desse processo, estão representadas na Figura 6. 


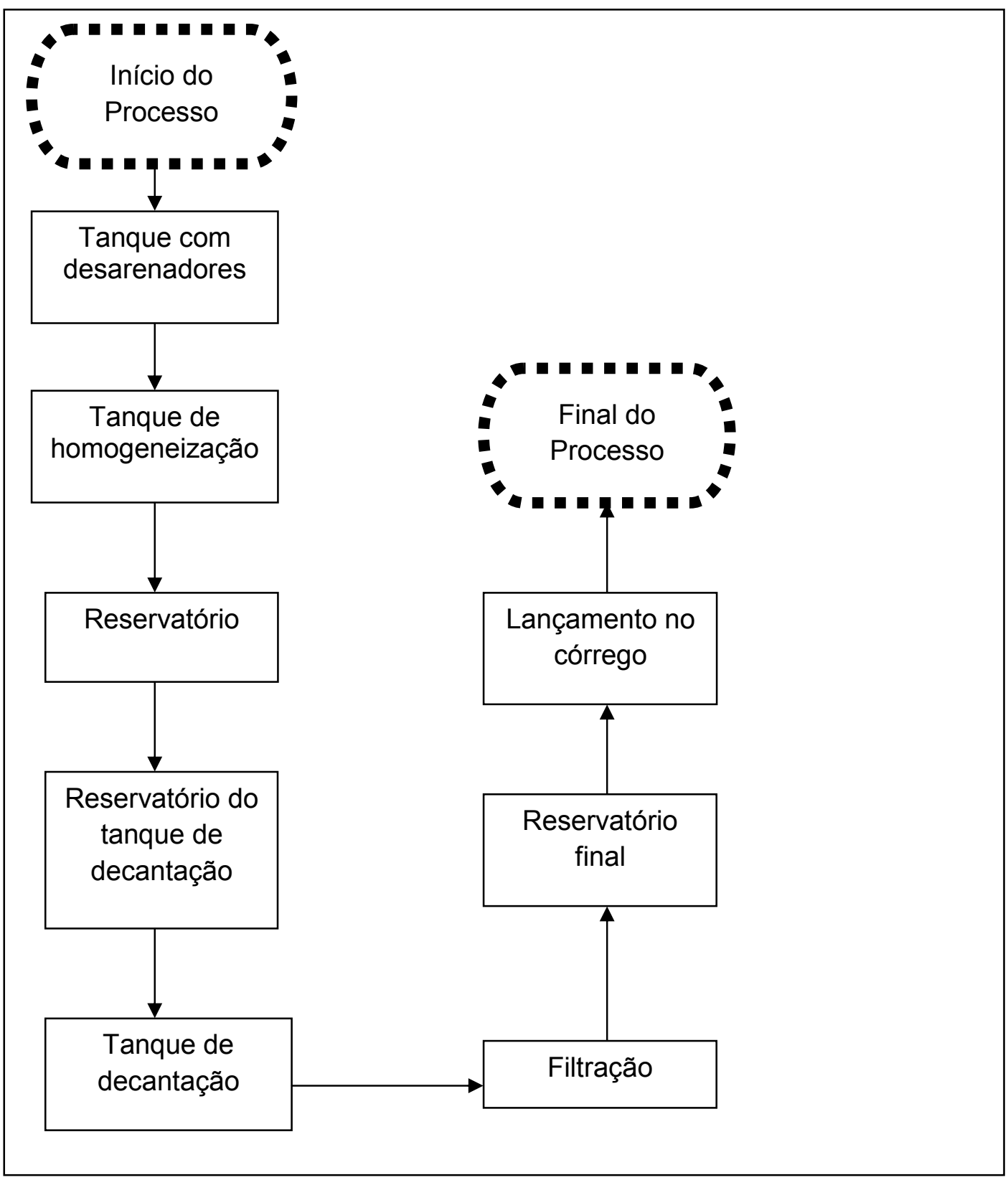

Figura 6: Fluxograma do processo de tratamento do efluente.

Fonte: Elaboração própria, 2011

\subsection{Análise do efluente realizada na lavanderia}

As análises do efluente realizadas pela Química na lavanderia são: pH e temperatura. Estas análises são realizadas diariamente, no intervalo de 1 hora e os resultados são armazenados em uma planilha de monitoramento, conforme Quadro 1. Além das análises, é realizado o controle de vazão da água que chega ao tanque de tratamento. 
Quadro 1: Planilha de monitoramento dos parâmetros analisados

\begin{tabular}{|l|l|l|l|l|l|l|l|l|l|l|}
\hline Hora & $08: 00$ & $09: 00$ & $10: 00$ & $11: 00$ & $12: 00$ & $13: 00$ & $14: 00$ & $15: 00$ & $16: 00$ & $17: 00$ \\
\hline $\mathrm{pH}_{\mathrm{i}}$ & & & & & & & & & & \\
\hline $\mathrm{pH}_{\mathrm{t}}$ & & & & & & & & & & \\
\hline $\mathrm{pH}_{\mathrm{f}}$ & & & & & & & & & \\
\hline $\mathrm{Vm}^{3} / \mathrm{h}$ & & & & & & & & & \\
\hline $\mathrm{T}^{\circ} \mathrm{C}_{\mathrm{i}}$ & & & & & & & & & \\
\hline $\mathrm{T}^{\circ} \mathrm{C}_{\mathrm{f}}$ & & & & & & & & & & \\
\hline $\mathrm{pH}_{\mathrm{i}}=\mathrm{pH}$ inicial $/ \mathrm{pH}=\mathrm{pH}$ tanque $/ \mathrm{pH}_{\mathrm{f}}=\mathrm{pH}$ final \\
$\mathrm{Vm}^{3} / \mathrm{h}=$ Vazão $\mathrm{m}^{3} / \mathrm{h}$ \\
$\mathrm{T}^{\circ} \mathrm{C}_{\mathrm{i}}=$ temperatura inicial $/ \mathrm{T}^{\circ} \mathrm{C}_{\mathrm{f}}=$ temperatura final
\end{tabular}

Fonte: Elaboração própria, 2011

São analisados o pH inicial, do tanque e o final. $\mathrm{O}$ pH inicial refere-se ao efluente que fica armazenado no reservatório antes de seguir para o tanque de tratamento. $\mathrm{O} \mathrm{pH}$ do tanque corresponde ao efluente após a adição dos produtos químicos e o $\mathrm{pH}$ final refere-se ao efluente do reservatório final. As temperaturas iniciais e finais também são analisadas.

A vazão ideal do efluente que chega ao reservatório onde são adicionados os produtos químicos deve estar entre 15 e $25 \mathrm{~m}^{3} / \mathrm{h}$, a temperatura da água não interfere no processo e o $\mathrm{pH}$ deve estar entre 6,0 e 9,0 . Quando o pH não está ideal, são adicionados os produtos químicos necessários para que ele possa ser ajustado.

\subsection{Pontos de coleta}

Para a realização das análises físico-químicas e bacteriológicas foram realizadas três coletas. Em cada uma foram coletadas duas amostras de $250 \mathrm{~mL}$ para análise dos parâmetros do efluente do processo de lavagem de roupas sem tratamento (entrada) conforme Figura 7 e duas amostras de $250 \mathrm{~mL}$ para análise do efluente após a passagem pela estação de tratamento (saída) de acordo com a Figura 8. Após as coletas, as amostras foram refrigeradas, cobertas com papel para evitar a entrada de luz e foram levadas em recipientes devidamente apropriados para os laboratórios onde foram analisadas 12 horas após. 


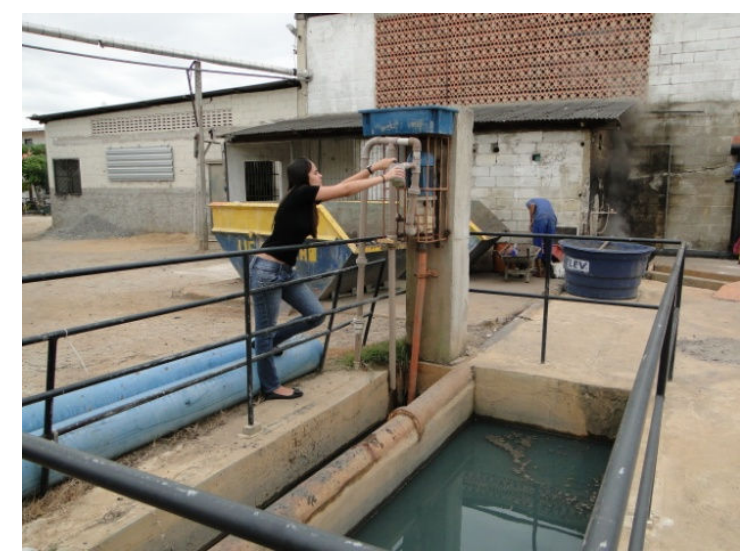

Figura 7: Ponto de coleta do efluente (entrada)

Fonte: Elaboração própria,

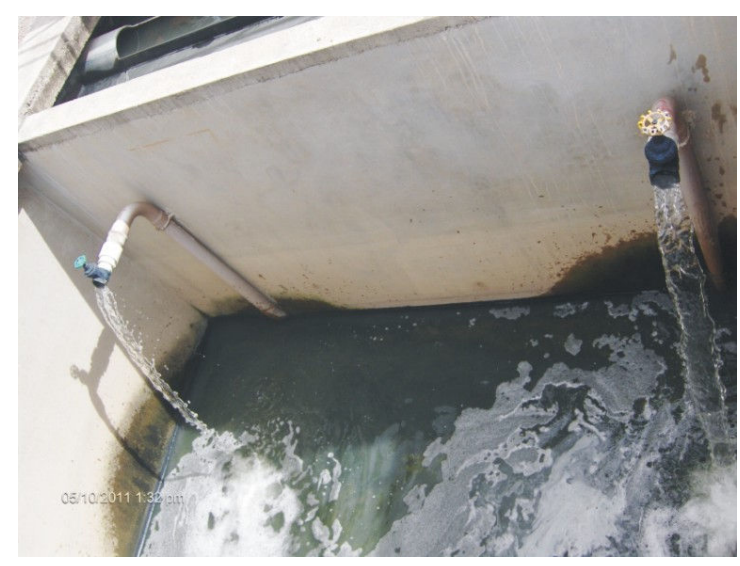

Figura 8: Ponto de coleta do efluente (saída)

Fonte: Elaboração própria,

\subsection{Análises físico-químicas do efluente}

As características da água estudada para esta pesquisa estão apresentadas no Quadro 2.

Quadro 2: Características da água

\begin{tabular}{|l|l|l|}
\hline Parâmetros & $\begin{array}{l}\text { Efluente antes tratamento } \\
(\text { Entrada) }\end{array}$ & Efluente tratado (Saída) \\
\hline $\mathrm{pH}$ & 6,02 & 6,68 \\
\hline Cor (UH) & 5.168 & 100 \\
\hline Turbidez (UT) & 306 & 26 \\
\hline Cloro residual (mg/L) & 0,34 & 0,12 \\
\hline Óleos e Graxas (mg/L) & 6,3 & 4,0 \\
\hline DBO (mg/L) & 27,8 & 11,3 \\
\hline Nitrogênio amoniacal (mg/L) & 0,84 & 0,45 \\
\hline Nitrato (mg/L) & 1,4 & 3,1 \\
\hline Nitrito (mg/L) & 0,1870 & 0,0452 \\
\hline Fósforo total (mg/L) & 2 & 0,09 \\
\hline Sólidos totais (mg/L) & 179 & 34 \\
\hline Sólidos fixos (mg/L) & 137 & 10 \\
\hline
\end{tabular}




\begin{tabular}{|l|l|l|}
\hline Sólidos voláteis $(\mathrm{mg} / \mathrm{L})$ & 42 & 24 \\
\hline $\begin{array}{l}\text { Coliformes termotolerantes } \\
(\mathrm{NMP} / 100 \mathrm{~mL})\end{array}$ & 1.100 & 0 \\
\hline
\end{tabular}

Fonte: Elaboração própria, 2011

De acordo com os padrões de qualidade estabelecidos pela NBR 13969/97 e levando em consideração a água de reúso classe 1 pode-se comprarar o efluente tratado conforme o Quadro 16.

Quadro 2: Comparativo do efluente tratado de acordo com a NBR 13969/97

\begin{tabular}{|l|l|}
\hline Padrões de qualidade & Efluente tratado \\
\hline Turbidez $<5$ UT & $26 \mathrm{UT}$ \\
\hline $\begin{array}{l}\text { Coliformes termotolerantes }<200 \mathrm{NMP} / 100 \\
\mathrm{~mL}\end{array}$ & 0 \\
\hline Sólidos dissolvidos totais $<200 \mathrm{mg} / \mathrm{L}$ & $\mathrm{NR} *$ \\
\hline pH entre 6 e 8 & 6,68 \\
\hline Cloro residual entre $0,5 \mathrm{mg} / \mathrm{L} \mathrm{e} 1,5 \mathrm{mg} / \mathrm{L}$ & $0,12 \mathrm{mg} / \mathrm{L}$ \\
\hline *NR= Não realizado & \\
\hline
\end{tabular}

Fonte: Elaboração própria, 2011

Os resultados encontrados mostram que as concentrações de coliformes termotolerantes e pH estão dentro dos padrões de qualidade. Entretanto, o parâmetro turbidez ficou acima do padrão estabelecido e o cloro residual abaixo.

De acordo com os parâmetros estabelecidos pelo Manual de Conservação e Reúso de Água em Edificações (ANA; FIESP, 2005) e utilizando como base a água de reúso classe 1 pode-se comparar o efluente tratado conforme o Quadro 4. 
Quadro 4: Comparativo do efluente tratado de acordo com o Manual de Conservação e Reúso de Água em Edificações

\begin{tabular}{|l|l|}
\hline Padrões de qualidade & Efluente tratado \\
\hline Coliformes fecais - Não detectáveis & NU** \\
\hline $\mathrm{pH}$ entre 6,0 e 9,0 & 6,68 \\
\hline Cor $\leq 10 \mathrm{UH}$ & $100 \mathrm{UH}$ \\
\hline Turbidez $\leq 2 \mathrm{UT}$ & $26 \mathrm{UT}$ \\
\hline Odor e aparência $-\mathrm{Não}$ desagradáveis & $\mathrm{NR} *$ \\
\hline Óleos e graxas $\leq 1 \mathrm{mg} / \mathrm{L}$ & $4,0 \mathrm{mg} / \mathrm{L}$ \\
\hline DBO $\leq 10 \mathrm{mg} / \mathrm{L}$ & $11,3 \mathrm{mg} / \mathrm{L}$ \\
\hline Compostos orgânicos voláteis - Ausentes & $\mathrm{NR} *$ \\
\hline Nitrato $<10 \mathrm{mg} / \mathrm{L}$ & $3,1 \mathrm{mg} / \mathrm{L}$ \\
\hline Nitrogênio amoniacal $\leq 20 \mathrm{mg} / \mathrm{L}$ & $0,45 \mathrm{mg} / \mathrm{L}$ \\
\hline Nitrito $\leq 1 \mathrm{mg} / \mathrm{L}$ & $0,0452 \mathrm{mg} / \mathrm{L}$ \\
\hline Fósforo total $\leq 0,1 \mathrm{mg} / \mathrm{L}$ & $0,09 \mathrm{mg} / \mathrm{L}$ \\
\hline Sólido suspenso total $\leq 5 \mathrm{mg} / \mathrm{L}$ & $\mathrm{NR} *$ \\
\hline Sólido dissolvido total $\leq 500 \mathrm{mg} / \mathrm{L}$ & $\mathrm{NR} *$ \\
\hline$*$ NR $=$ Não realizado & \\
\hline$* * N U=$ Não utilizado & \\
\hline
\end{tabular}

Fonte: Elaboração própria, 2011

Nota-se que os parâmetros referentes ao nitrato, nitrogênio amoniacal, nitrito e fósforo total estão de acordo com os padrões de qualidade estabelecidos. Porém, os valores de cor, turbidez, óleos e graxas e DBO e foram superiores.

Analisando o tratamento do efluente, observa-se que após a realização deste, os valores dos parâmetros reduziram, com exceção dos valores de $\mathrm{pH}$ e nitrato, porém ainda permaneceram dentro dos padrões exigidos. 
Durante a análise dos resultados, observou-se que o parâmetro turbidez apresentou altos valores. Isso pode ter ocorrido possivelmente devido a falhas no processo de filtração. Tal resultado fez com que os valores ficassem acima do preconizado pela norma.

Apesar do efluente não poder ser reutilizado no processo de lavagem de jeans, foi verificada a possibilidade do reúso em outros processos, como lavagem da área externa da empresa e dos banheiros. Entretanto, os parâmetros não ficaram dentro dos padrões para a reutilização.

\section{CONCLUSÕES}

Por meio das análises físico-químicas e bacteriológicas realizadas, foi possível observar que o efluente tratado não pode ser reutilizado no processo de lavagem de jeans, uma vez que alguns parâmetros ficaram fora dos padrões de qualidade estabelecidos. Portanto, o objetivo geral deste trabalho pode ser alcançado.

Em relação aos objetivos específicos, todos foram realizados de acordo com o estabelecido para alcançar o objetivo geral do trabalho.

Considerando o Manual de Conservação e Reúso de Água em Edificações, os parâmetros que ficaram fora dos padrões foram cor, turbidez, óleos e graxas e DBO, fazendo com que o reúso seja inviável

Sugere-se que a lavanderia realize o controle e monitoramento da qualidade e tratamento do efluente, realizando análises de todos os parâmetros que devem ser controlados para o reúso. Este controle possibilitaria o tratamento do efluente com os produtos apropriados para que os parâmetros que ficaram fora dos padrões de qualidade estabelecidos sejam adequados e o efluente possa ser reutilizado

Mesmo sendo necessário um investimento da lavanderia, o retorno econômico com a prática do reúso é viável, levando em consideração a economia de água e consequentemente a redução de custos que empresas que adotam esta prática como já mencionados durante o trabalho apresentaram.

\section{REFERÊNCIAS BIBLIOGRÁFICAS}

SOUZA, F. P. Ocupações irregulares em áreas de preservação permanente: um estudo de caso no município de Campos dos Goytacazes, RJ. Boletim do Observatório Ambiental Alberto Ribeiro Lamego, Campos dos Goytacazes, v.4, n.1, p.37-56, 2010.

BARBOSA, F. Ângulos da água: desafios da integração. 1 ed. Belo Horizonte: Editora UFMG, 2008. 366p.

MACHADO, C. J. S. Meandros do meio ambiente: os recursos hídricos no direito, na política, nos centros urbanos e na agricultura. 1.ed. Rio de Janeiro: E - Papers Serviços Editoriais , 2004. $124 \mathrm{p}$. 
MENEZES, Jean Carlo. Tratamento e reciclagem do efluente de uma lavanderia industrial. 2005. 105p. Dissertação (Mestrado) - Escola de Engenharia, Universidade Federal do Rio Grande do Sul, Porto Alegre, 2005.

PINHEL, A. S. et al. Projeto de aproveitamento água de chuva em escolas - A2C. In: CAPTAÇÃo E MANEJO DE ÁGUA DE CHUVA, 6, 2007, Belo Horizonte. Simpósio. Belo Horizonte: Águas de Chuva: Pesquisas, Políticas e Desenvolvimento Sustentável, 2007.

BEEKMAN, G. B. Gerenciamento integrado dos recursos hídricos. 1 ed. Brasília: IICA, 1999. $64 \mathrm{p}$.

PERTEL, Monica. Caracterização do Uso da Água e da Energia Associada à Água em uma Edificação Residencial Convencional e uma Dotada de Sistema de Reúso de Águas Cinza. 2009. 104p. Dissertação (Mestrado) - Centro Tecnológico, Universidade Federal do Espírito Santo, Vitória, 2009.

LEITE, Ana Maria. Reúso de água na gestão integrada de recursos hídricos. 2003. 120p. Dissertação (Mestrado) - Universidade Católica de Brasília, Brasília, 2003.

FERREIRA, A.; CUNHA, C. Sustentabilidade ambiental da água consumida no Município do Rio de Janeiro, Brasil. Rev Panam Salud Publica, Guarulhus, v.4, n.1, p.93-99, 2005.

ASSOCIAÇÃO BRASILEIRA DE NORMAS TECNICAS. Tanques sépticos unidades de tratamento complementar e disposição final dos efluentes líquidos - projeto, construção e operação: NBR 13.969. Rio de Janeiro, 1997. 60p.

FEDERAÇÃO DAS INDÚSTRIAS DO ESTADO DE SÃO PAULO. Manual Conservação e reúso de água. São Paulo: Prol Editora Gráfica, 2005. 92p.

ANA, FIESP \& SindusCon-SP. Conservação e Reúso da Água em Edificações. São Paulo: Prol Editora Gráfica, 2005. 151p.

BAZZARELLA, Bianca. Caracterização e aproveitamento de água cinza para uso não-potável em edificações. 2005. 165p. Dissertação (Mestrado) - Centro Tecnológico, Universidade Federal do Espírito Santo, Vitória, 2005.

AFONSO, C. M. Sustentabilidade: caminho ou utopia? 1 ed. São Paulo: Annablume, 2006. 74p.

SILVA, E. L.; MENEZES, E. M. Metodologia da Pesquisa e Elaboração de Dissertação. 3.ed. Florianópolis: Laboratório de Ensino a Distância da UFSC, 2001. 121p.

GIL, A. C. Como Elaborar Projetos de Pesquisa. 4.ed. São Paulo: Atlas, 2008. 175p.

MIGUEL, P. A. C. Estudo de caso na engenharia de produção: estruturação e recomendações para sua condução. Revista Produção, v. 17, n.1, p. 216-229, 2007.

MIGUEL, P. A. C. et al. Metodologia de pesquisa em engenharia de produção e gestão de operações. 1 ed. Rio de Janeiro: Elsevier, 2010. 248p.

MENEZES, Jean Carlo. Tratamento e reciclagem do efluente de uma lavanderia industrial. 2005. 105p. Dissertação (Mestrado) - Escola de Engenharia, Universidade Federal do Rio Grande do Sul, Porto Alegre, 2005. 
NAVACHI, José Aparecido. Reutilização dos efluentes tratados: caso de uma lavanderia industrial. 2002. 89p. Dissertação (Mestrado) - Centro de Ciências Tecnológicas, Universidade Regional de Blumenau, Blumenau, 2002.

AMERICAN WATER WORKS ASSOCIATION. Standard Methods for Examination of Water and Wastewater, 21 Edition. Washigton: APHA, 2005.

AGOSTINI, Rodolfo dos Santos. Avaliação do desempenho e da viabilidade econômica de um sistema de reúso de água cinza em um edifício residencial de alto padrão. 2009. 69p. Trabalho de Conclusão de Curso (Bacharelado), Departamento de Engenharia Ambiental, Universidade Federal do Espírito Santo, Vitória, 2009.

Portal UOL. Matéria divulgada pela Folha Online. Internet. Disponível em: http://www1.folha.uol.com.br/folha/mundo/ult94u93416.shtml. Acesso em: 11 mar 2011.

SECKLER, D.; BARKER, R.; AMARASINGHE, U. Water Scarcity in the Twenty-first Century. Water Resources Development, v.15, n. 1-2, p.29-42, 1999.

PAZ, V. P. da S.; TEODORO, R. E. F.; MENDONÇA, F. C. Recursos hídricos, agricultura irrigada e meio ambiente. Revista Brasileira de Engenharia Agrícola e Ambiental, Campina Grande, v. 4, n. 3, p.465-473, 2000.

TUNDISI, J. G. Recursos hídricos no futuro: problemas e soluções. Revista Estudos Avançados, São Paulo, v.22, n.63, p.7-16, 2008.

HINZ, R. T. P.; VALENTINA, L. V. D.; FRANCO, A. C. Monitorando o desempenho ambiental das organizações através da produção mais limpa ou pela avaliação do ciclo de vida. Revista Produção Online, Florianópolis, v.7, n.3, 2007.

BETTINE, S. do C.; DEMANBORO, A. C. Sustentabilidade hídrica: desafios para conglomerados urbanos. Revista OLAM - Ciência \& Tecnologia, Rio Claro, v.8, n.3, p.68-84, 2008.

BORDONALLI, A. C. O.; MENDES, C. G. N. Reúso de água em indústria de reciclagem de plástico tipo PEAD. Revista Engenharia Sanitária e Ambiental, Rio de Janeiro, v.14, n.2, p.235-244, 2009.

JUNIOR, A. O.; PAWLOWSKY, U. Avaliação de tecnologias avançadas para o reúso de água em indústria metal-mecânica. Revista Engenharia Sanitária e Ambiental, Rio de Janeiro, v.12, n.3, p.305-316, 2007.

ZULAUF, W. E. O meio ambiente e o futuro. Revista Estudos Avançados, São Paulo, v.14, n.39, p.85-100, 2000.

LAVRADOR FILHO, J. Contribuição para o entendimento do reúso planejado das águas e algumas considerações sobre suas possibilidades no Brasil. Dissertação (Mestrado) - Escola Politécnica, Universidade de São Paulo, São Paulo, 1987.

MANCUSO, P.; SANTOS, H. Reúso de água. 1.ed. São Paulo: Manole, 2003. 579p.

Portal Universidade da Água. Internet. Disponível em: http://www.uniagua.org.br/public html/website/default.asp?tp=3\&pag=reúso.htm. Acesso em: 03 mar 2011. 
Portal CIRRA - CENTRO INTERNACIONAL DE REFERÊNCIA EM REÚSO DE ÁGUA.

Internet. Disponível em: http://www.usp.br/cirra/br tipos\%20de\%20reuso.html. Acesso em: 04 mar 2011.

HESPANHOL, I. Um novo paradigma para a gestão de recursos hídricos. Revista Estudos Avançados, São Paulo, v.22, n.63, p.131-158, 2008.

REBOUÇAS, A. C. et al. Águas doces no Brasil - Capital ecológico, uso e conservação. 3 ed. São Paulo: Escrituras, 2006. 720 p.

MACEDO, R. Reutilização da água é vantagem competitiva para a indústria. Agência SEBRAE de Notícias. Distrito Federal, 2007.

FIRJAN, SEBRAE. Manual de Conservação e Reúso de Água na Indústria. Rio de Janeiro: DIM, 2006. 31p. 